the clinical picture showed apparent stabilization of the abnormal neurological signs in these patients, and the 15-yearold boy has so far lived for more than four years since the onset of the illness.

Subacute sclerosing leucoencephalitis is accompanied by an increase and a qualitative change in the cerebrospinal fluid gamma-G-globulins (Kolár, 1966a) and by appearance of autoantibodies against the brain-tissue antigen in the C.S.F. of subacute sclerosing leucoencephalitis patients (Běhounková et al., 1966). The symptoms and laboratory manifestations of subacute sclerosing leucoencephalitis may have a remittent course. Other manifestations of the disease include splenomegaly, hepatomegaly, and pathological changes, mainly in the cathodic part of the serum gamma-G-globulins (Kolář, 1966c ; Koláŕ, Obručník, Fárková, Dvořák, and Musil, 1967).

Examination of biopsy or necropsy brain tissue from patients with subacute sclerosing leucoencephalitis has shown mainly perivenous collection of mononuclear cells which probably contain glycolipoprotein complexes, since these fluoresce when examined by ultraviolet light. Moreover, the presence of abnormal gamma-G-globulins in these specimens from patients with subacute sclerosing leucoencephalitis has also been shown (Kolář, Dencker, Obručník, Cerná, and Skatula, 1966).

The perivascular mononuclear infiltrates in the brain, persisting for months to years, the increase and the qualitative changes of gamma-G-globulins in brain tissue, the participation of the extraneural reticuloendothelial system in the development of subacute sclerosing leucoencephalitis, together with the presence of antibodies against a brain-tissue extract used as antigen in the cerebrospinal fluid, all suggest a neuroimmunopathological basis for this disease. This process seems to be not completely analogous with the immunological events leading to experimental allergic encephalomyelitis.

Involvement of the thymus in the development of autoimmune processes, particularly those in which delayed hypersensitivity is concerned, is now generally accepted (Good, Finstad, Peterson, Kellum, and Surtherland, 1965 ; Loghem, 1965). Nevertheless, thymectomy, especially in older subjects, does not prevent the appearance of autoantibodies (Kerr, Duran, Thomas, and Wright, 1965). So far the therapeutic effects of thymectomy in myasthenia gravis have not necessarily been found to be beneficial. Some improvement after thymectomy was described in a patient with systemic lupus erythematosus
(Mackay, Goldstein, and McConchie, 1963), but this could be attributed to prednisolone therapy.

The improvement in the neuropsychiatric symptoms in our patient with subacute sclerosing leucoencephalitis is noteworthy, though it can hardly be ascribed to the corticosteroid therapy, which was given in small doses. Nevertheless, a spontaneous remission of the subacute sclerosing leucoencephalitis, which was accompanied also by a fall in the cerebrospinal fluid gammaG-globulins, cannot be excluded in this case.

Thymic hyperplasia in patients with subacute sclerosing leucoencephalitis suggests that the "central" lymphoid tissue may play a part in the development of the disease. Possibly the thymus influences the development of subacute sclerosing leucoencephalitis unfavourably by supporting the autoimmune histotoxic process, but the right moment to recommend thymectomy in patients with subacute sclerosing leucoencephalitis will be determined only by careful study of further cases of the disease.

\section{Summary}

Enlargement of the thymus may be found in some patients in the course of subacute sclerosing leucoencephalitis. We describe a case of subacute sclerosing leucoencephalitis treated by thymectomy in which considerable improvement resulted.

We thank Professor V. Rapant, M.D., Dr.Sc., head of I Clinic of Surgery, Palacký University, Olomouc, for his co-operation.

\section{REFERENCES}

Bĕhounková, L., Kadlec, A., and Koláł, O. (1966). Acta Univ. Olomuc.,

Good, R. A., Finstad, J., Peterson, R. D. A., Kellum, M., and Surtherland, D. E. R.' (1965). Molecular and Cellular Basis of Antibody Formation. Prague.

Kerr, J. H., Duran, C. G., Thomas, H., and Wright, R. (1965). ₹. Neurol. Neurosurg. Psychiat., 28, 429.

Koláx, O. (1966a). Klin. Wschr., 44, 279.

(1966b). Wien. Z. Nervenheilk., Suppl. No. 1, p. 208.

(1966c). Z. Immun. Allergieforsch., 131, 236.

Dencker, S. J., Obručnik, M., Cerná, I., and Skatula, Z. (1966).

Dtsch. Z. Nervenheilk., 188, 222.

Obručník, M., Fárková, H., Dvořák, V., and Musil, J. (1967). ₹. neurol. Sci. In press.

Loghem, J. J. van (1965). Ser. Haematol., 9, 1. ${ }_{\text {Mackay, I. R., Goldstein, G., and McConchie, I. H. (1963). Brit. med. }}$ Mackay, I. R., Goldstein, G., and McConchie, I. H. (1963). Brit. med. Pĕgłrim, R., Ríha, V., and Simeček, C. (1957). Rozhl. Tuberk., 17, 100.

\title{
Renal Colic
}

\author{
JAMES A. RHIND,* F.R.C.S.
}

Since 1958 an "immediate" intravenous pyelogram (I.V.P.), taken while the pain is actually present, has been used in the routine investigation of cases of suspected renal colic admitted to the Pontefract General Infirmary. This is a busy hospital, and it has often been necessary for the consultants to delegate to junior staff the responsibility for the initial diagnosis and supervision of the $x$-ray films, which were often taken by junior radiographers during the evening and the night. The details of the $x$-ray examination have varied, but in general we have taken a control film, and films 10 and 30 minutes after the injection of the intravenous medium. Further films were taken until the ureter was outlined; this may not happen until as long as 24 hours, but the rate of appearance of the nephrogram can be a guide to the timing of the later films.

While a typical attack of renal colic can be recognized confidently, in the atypical attack an immediate intravenous pyelo- gram showing delayed excretion, a nephrogram, and slow filling of the kidney drainage system compared with the normal side provides impressive confirmation of the obstruction to the kidney and permits the use of strong analgesics. The further management of the case depends on the demonstration of the cause of the obstruction.

\section{Results}

The results in the 146 cases in which immediate I.V.P. was carried out were: stones in 84 cases, abnormal $x$-ray films in 27 , normal $x$-ray films in 31 , and other diseases in 4 .

* Consultant Surgeon, Pontefract and Castleford Hospital Group, Pontefract, Yorkshire. 


\section{Stones}

We were impressed by the number of stones revealed by this routine. In some cases several films were required before an apparent phlebolith in the pelvis was indicated as a calculus by coincidence with the termination of a dilated ureter, the diagnosis being confirmed by the disappearance of the shadow after passage of a stone. In other cases a large shadow was quickly proved to be a ureteric calculus. During the same period ureteric calculi were discovered in outpatients referred after an attack of renal colic or with other urinary symptoms, and the management of these cases (called "late I.V.P.") is compared with the cases of immediate I.V.P. in the accompanying Table. A further group of cases we have called "delayed I.V.P." These patients were admitted to hospital with renal colic, but an immediate I.V.P. was not taken because either the pain had ceased or pressure of work in the $x$-ray department prohibited the examination. In these cases the I.V.P. was usually taken about four to seven days after admission.

\begin{tabular}{|c|c|c|c|c|c|c|c|}
\hline \multirow{4}{*}{-} & \multicolumn{5}{|c|}{ Fate of Calculi in the Ureter } & & \\
\hline & \multirow{3}{*}{$\begin{array}{l}\text { Size of } X \text {-ray } \\
\text { Shadow of } \\
\text { Stone }\end{array}$} & \multicolumn{6}{|c|}{ I.V.P. } \\
\hline & & \multicolumn{2}{|c|}{ Immediate } & \multicolumn{2}{|c|}{ Delayed } & \multicolumn{2}{|c|}{ Late } \\
\hline & & Passed & Op. & Passed & Op. & Passed & Op. \\
\hline \multirow[t]{2}{*}{$\begin{array}{l}\text { Abdominal } \\
\text { ureter }\end{array}$} & $\begin{array}{l}3 \mathrm{~mm} \text {. or less } \\
4 \text { ", more } \\
\text { Not known }\end{array}$ & $\begin{array}{l}6 \\
2 \\
3\end{array}$ & $\begin{array}{l}1 \\
6 \\
2\end{array}$ & & $\begin{array}{l}1 \\
1\end{array}$ & & $\begin{array}{l}1 \\
5 \\
2\end{array}$ \\
\hline & Total & 11 & 9 & 0 & 2 & $\mathbf{0}$ & 8 \\
\hline \multirow[t]{2}{*}{$\begin{array}{l}\text { Pelvic } \\
\text { ureter }\end{array}$} & $\begin{array}{l}2 \mathrm{~mm} . \\
3-5 \mathrm{~mm} . \\
6 \mathrm{~mm} \text {. or more } \\
\text { Not known }\end{array}$ & $\begin{array}{r}32 \\
21 \\
2 \\
6\end{array}$ & 3 & $\begin{array}{l}2 \\
4 \\
1 \\
4\end{array}$ & 1 & $\begin{array}{l}3 \\
8 \\
7\end{array}$ & $\begin{array}{l}1 \\
3 \\
3\end{array}$ \\
\hline & Total & 61 & 3 & 11 & 1 & 19 & 7 \\
\hline
\end{tabular}

It is apparent that most of the stones revealed by the immediate I.V.P. are small, are at the lower end of the ureter, and pass spontaneously. Operative intervention was more common when the immediate I.V.P. showed a stone in the abdominal ureter ; ureterolithotomy in this area is easy and safe, and failure of the stone to move for a few days was usually taken as an indication for operation. How many of these stones would have passed is uncertain, but the occasional stone which moved slowly was a source of anxiety for weeks. The late I.V.P. series showed a much smaller proportion of small stones and more of these cases were treated by operation; in four cases the kidney was so damaged that nephrectomy was performed. It would seem that the agonizing pain of renal colic requiring admission to hospital implies a healthy kidney and the recent movement of a small stone to the ureter, from which it will probably soon pass. The kidney that has been damaged by the growth of a larger calculus in the ureter can manage only a feeble protest which brings the patient to the outpatient clinic.

\section{Abnormal X-ray Films}

In 27 cases the immediate I.V.P. showed some or all of the signs of obstruction-namely, delayed excretion, nephrogram, hydronephrosis, and delayed emptying of the ureter-but without the shadow of a stone being visible. In five of these cases the examination was not continued long enough to demonstrate the whole ureter. In two the patient failed to empty the bladder, and the lower end of the ureter was obscured. In only one case did we find that faecal and gas shadows prevented adequate examination of the ureter. Thus in 19 there was evidence of obstruction without stones. Two of these patients subsequently passed stones. In the stone series occasionally a ureteric shadow disappeared during the course of the examination, with passage of a calculus, but the signs of obstruction -persisted for a little time. We are prepared to accept the thesis that in the absence of other disease renal colic is always due to the presence of a stone.

\section{Normal X-ray Films}

If the pain of renal colic is due to a rise in pressure in the ureter and kidney pelvis, it is difficult to see how this can occur without radiological abnormality. In 31 cases the immediate I.V.P. was normal though the diagnosis of renal colic seemed well established by a typical history, the presence of red cells on microscopy of the urine, redness and swelling of the ureteric orifice on cystoscopy, or the passage of a calculus. In some cases an overzealous junior resident carried out an immediate I.V.P. even though the patient's pain had disappeared on admission to hospital. In other cases the $x$-ray department could not arrange an I.V.P. for some hours and the pain disappeared during the period of waiting. Strong analgesics are required for the relief of the pain of renal colic and it may be impossible to say whether the disappearance of the pain is due to the analgesic or the actual relief of the obstruction. Each of these explanations probably applied in some cases, but unfortunately our records are not detailed enough to be sure that they explain all the normal I.V.P.s. Nevertheless, we are left with a strong feeling that a normal I.V.P. taken while the patient has continuing pain makes the diagnosis of renal colic unlikely.

\section{Other Diseases}

This series included one case of renal tumour with haematuria, pyelonephritis, massive hydronephrosis, and renal arterial embolism.

\section{Discussion}

An immediate I.V.P. for all cases of renal colic imposes a heavy strain on an $x$-ray department, but the value of the examination justifies the procedure. A normal I.V.P. requires serious reconsideration of the diagnosis, while the proof of renal obstruction reassures the doctor in continuing analgesia. The demonstration of a small stone $(4 \mathrm{~mm}$. or less) at the lower end of the ureter-and this will be the case in a great numberallows the patient to be sent home if the general practitioner will provide suitable analgesia. It is important that these patients are seen in the outpatient clinic until the stone has been passed. A larger stone $(4 \mathrm{~mm}$. in the upper ureter or $6 \mathrm{~mm}$. in the pelvic ureter) may need early operation unless it is moving quickly. Perhaps the general adoption of this policy might prevent the tragedy of the late case which requires removal of a destroyed kidney rather than ureterolithotomy.

\section{Summary}

Investigation of 146 cases of renal colic by immediate intravenous pyelography showed that most cases are due to calculi, and that the few that need operation can be selected at an early stage. 